\title{
Unveiling the intricate public-private interplay in next generation communications
}

\section{Covering the full circle: political vs. economic criteria in the deployment of telecommunication networks}

For most of the last century, telephone services and telecommunication services more generally were provided by national companies operating as monopolies. The monopolist was in charge of deploying the networks, using criteria that were often more political than economic. The generalisation tends to hold internationally, although at certain times and in certain places, it has not been true. The United States is the most prominent exception.

In the mid-1980s, the first tentative efforts to reform the sector began. Once these efforts intensified and spread, they led to an extraordinary transformation process that in most cases included the privatisation of the monopolistic companies. Barely a decade after the first instances of privatisation, with markets being progressively liberalised and companies operating in competition, it seemed that the direct construction of networks by public bodies or companies under their control was definitely left behind.

However, almost at the same time as the privatisation process reached its zenith of activity, new policies of unquestionable influence on the industry emerged. The rise of what has been called the knowledge economy or new economy has reinforced the role of telecommunications as a strategic investment. The consensus regarding the importance of telecommunications has changed the reasoning at play. It no longer includes the existence of an adequate infrastructure as a factor affecting regional development. Instead, its absence is considered a sign of underdevelopment. As a result, governments pay particular attention to telecommunications. This renewed interest includes direct intervention in network deployment.

The programmes intended to facilitate the development of the information society have been used as an umbrella for most of these resuscitated initiatives. Almost all countries, including a good number of the less developed ones, have launched their own proposals for adapting their economies to the new socio-economic paradigm that is taking shape. In these plans, "universal access" to advanced telecommunications services tends to occupy a prominent position. Generally, it is assumed that private companies will carry out most of the tasks required to reach this objective. However, there has been frequent allocation of public funds for the construction of infrastructure in places where a private initiative will occur late or not at all. Furthermore, similar projects have been carried through autonomously without support from any national plans and even in places where telecommunication operators maintain the availability of broadband connections under normal market conditions.

The overall scenario is becoming even more complex. Digital plans and agendas are replacing "first-generation" initiatives promoting the creation of an information society, prompting us to envision a not-so-distant future in which everyone will enjoy access to hundreds of megabytes. Next-generation access networks are the new leitmotiv. Problems related to their deployment are considered conceptually distinct from those of "traditional" broadband service. These are problems that many would consider insurmountable without public involvement, which puts more stress on policymakers.

In short, barely a decade after the (widespread) opening of the markets was largely completed, the scenario of public participation in the deployment of telecommunication networks seems to have radically changed again. More and more networks reliant on public support will likely appear globally. 


\section{The new features of the public "comeback" in the deployment of communication networks}

One of the most significant characteristics of this public "comeback" in the deployment of telecommunication networks is the fact that the decisions are being made, in most cases, by public entities at a "lower" level than that of the central government: regional authorities and especially local or town councils. However, this is not a completely new phenomenon. Although decisions were usually centralised during the monopoly era, examples of small local operators can be found in some countries. ${ }^{1}$

From a technological standpoint, the commercial maturity of some wireless standards, along with the resulting cost reductions, has actually multiplied the number of cases of broadband public networks using the radio spectrum. ${ }^{2}$ However, wireless technologies are not the only ones being used. There exist many examples of public administrations having driven forward or contributed to the deployment of cable or fibre. Indeed, the scale is tilting towards wired technologies as nextgeneration access networks are introduced into the formula. ${ }^{3}$

More importantly, there are no common rules governing how to sponsor the construction of these networks or manage them once they are completed. The strategies being deployed are diverse and basically depend on the specific circumstances of each case. This panoply of possibilities is part of what leads us to talk about public-private interplay.

The second factor that encourages this focus is the array of orher policy instruments that can support the development of next-generation communications. Many digital policies (elnclusion, eHealth, eGovernment, and eParticipation) share the same basic axiom of preventing exclusion, which was originally part of the universal service approach, although a more balanced view of access/supply and adoption/demand is now prevalent. Therefore, the relationship between public and private can (and should) be put in a wider, more social and citizen-centric context. ${ }^{4}$ Understanding these new relationships is key to the development of next-generation communications because they are no longer isolated from issues of general socio-economic welfare. All of this suggests new possible spaces for public-private interplay in next-generation communications, spaces that undoubtedly merit further research.

\section{Scanning the special issue}

As mentioned before, the role assigned to the public and private sectors in most recent telecommunications policies entails as many variations as there are countries, regions or contexts. What is more, working from a relatively uniform theoretical framework based on the pre-eminence of market rules, approaches to public involvement in telecommunications have been very pragmatic. This special issue has tried to gather evidence and lessons from some of the more conspicuous example cases while simultaneously acknowledging that we are beginning a "new wave" of public involvement and that it is probably still too early to attempt to compose a complete record of all of the required data or to conduct a conclusive analysis.

Gómez-Barroso and Feijóo set the scene in their introductory paper "A conceptual framework for public-private interplay in the telecommunications sector". The paper addresses how justifications of public action that would apply to any area of economic activity created the paradigm for the public-private relationship in the telecommunications sector and how, subsequently, public activity in the telecommunications industry has undergone important transformations during the last decade. The authors conclude that the public and private sectors must be understood as mixed and cooperative rather than antagonistic and substitutive. However, in their opinion, apart from this general idea, few other universal rules can be drawn up: there is no single recipe for fruitful public-private collaboration, and the same policy will probably not work for every location. This means that the definition of public and private roles is a long-term issue for the sector that will remain important for the next few years, and indeed, it is a recurring idea in each of the papers in this special issue.

The specific role of public-private partnerships in the development of broadband infrastructures is explored in the paper by Henten and Falch entitled "Public-private partnerships (PPP) as tool for stimulating investments in broadband". The paper uses several main cases to examine the PPP concept as such. Whereas the PPP discourse has generally been focused on the idea of private companies taking over and cooperating with public organisations in the delivery of services to citizens, the PPP discourse in the telecommunications arena clearly tends to go in another direction. The paper stresses the current emphasis on infrastructure building vs. use and applications, services and content development. Two major types of policy initiatives stand out in this context: namely, economic support for infrastructure build-out and universal service policies. These do not constitute entirely new trends given that, on a smaller scale during a number of years, public money has been used for broadband projects. However, there has been a considerable increase in the funds allocated.

\footnotetext{
I In Bolivia and Finland, for example, consumer cooperatives have been the only mechanism providing local telecommunication services nationwide for many years (see Calzada and Dávalos, 2005, for Bolivia; Nattermann and Murphy, 1998, for Finland).

${ }^{2}$ In 2005-2006, much was written about municipal Wi-Fi. See, for example. Gibbons and Ruth (2006) or Strover and Mun (2006) or. for more recent research, Mandviwalla et al. (2008) or Goth (2009).

${ }^{3}$ Particularly illustrative to this respect are the Guideines for the application of State aid rules in reiation to the rapid deployment of broadband networks that the European Commission published on September 30, 2009. See an analysis in Gómez-Barroso and Feijóo (2010).

4 See, for example, Gauld, Goldfinch, and Horsburgh (2010).
} 
The various dimensions of choice involved in the allocation of public funds to promote investment in very high speed broadband are the guiding focus of the paper by Cave and Martin on "Motives and means for public investment in nationwide next generation networks". The paper considers nationwide broadband plans developed in Australia, New Zealand and Singapore, in each of which industrial policy appears to be the major objective along with equity goals and the resolution of problems related to the incumbents' legacy assets. The paper emphasises some of the difficulties and uncertainties associated with public investment in NGAs in particular, as follows: clarity regarding goals, the degree to which public investment can be used to leverage private investment, the ways of providing services in areas not covered by fibre, the high degree of consensus among the major operators, and the potentially beneficial results of some local initjatives.

Two other cases that can teach us about the dynamics of public involvement in broadband infrastructure deployment are the regional and municipal networks build-out processes that have occurred in the Netherlands and ltaly. Nucciarelli, Sadowski and Achard, in their paper "Emerging models of public-private interplay for European broadband access: evidence from the Netherlands and ltaly", describe how the interaction between public and private stakeholders can facilitate local broadband initiatives. The authors explain how this interaction has been vital in aligning the interests of different private and (semi-)public parties, as they work to design the network and aggregate sufficient demand for broadband services. The paper argues that unlike traditional forms of government procurement, PPP can be used to allocate costs and risks to make the initiatives sustainable (especially in financial terms), even assuming major uncertainties related to demand and technology.

Risk and uncertainty have always been factors in the interplay between public and private in this context. Fredebeul-Krein and Knoben in their paper "Long term risk sharing contracts as an approach to establish public-private partnerships for investment into next generation access networks", reveal how market uncertainty (in terms of demand for higher bandwidth, willingness to pay and alternative infrastructure development) can combine with regulatory uncertainty (regarding future wholesale and retail regulation) to negatively affect investment decisions regarding future NGA infrastructure. The paper explains that long-term risk-sharing contracts including long-term and shortterm prices for NGA investments are an appropriate approach for PPP. Contract revenues would take into account (the specific systematic) risk involved at the time of NGA network deployment, and this risk would be shared among a variety of stakeholders, thus creating a system that would resemble risk-sharing when investments in NGA were cooperatively undertaken. From the perspective of this paper, the proposed long-term risk-sharing model does have some notable advantages over the traditional regulatory approach, under which only risk-free short-term contracts are allowed.

No account of public-private interplay in telecommunications can be considered as complete without a detailed examination of the most paradigmatic cases to date: Australia and New Zealand. Given present research on the subject of these two cases in his paper "Take your partners: public private interplay in Australian and New Zealand plans for next generation broadband". The paper puts these complex and controversial forms of interplay in context, demonstrating three trends: a shift away from the liberalisation and privatisation policy consensus of the last two decades; a shared convictions about the anticipated magnitude of fast broadband's economic and social benefits and about the need for wholesale-only fixed line network operation to maximise those benefits; and the unlikely influence of the global financial and economic crisis in stimulating investment in particular infrastructures seen as critical to the national economies that emerge from it.

One of the main conclusions of this last paper may well represent a general conclusion regarding the whole issue: "The broadband arms race that has so galvanized telecommunications policy is global ... [but] Taking fibre all the way to homes and businesses is about nation-building and the future ... Convinced about the scale of their economic and social benefits, frustrated by the pace of investment under existing regulatory structures, attracted by the apparent progress made in places like Korea and Japan where industrial policy has been vigorously pursued, some governments have contemplated sharp changes to the policies of the last two decades ..." Sharp and multifaceted changes. Interplay, therefore, seems to be the right word to describe the kind of processes involved in setting up public-private relationships to support new telecommunications broadband infrastructures.

\section{Tentative conclusion: a research programme investigating public involvement in the deployment of telecommunication networks}

The phenomena described throughout this special issue are highly relevant in both their practical qualities (as regards their impact on markets and society) and their theoretical aspects (discussions of appropriateness and validity). They help to provide a clearer picture of the new public-private interplay in telecommunications, which is the intended purpose of this special issue.

However, as most of the papers emphasise, there is still considerable room for additional analysis, integrating the description of the current situation with the examination of past experiences and new data; in this effort, the final objective becomes to predict what future results could be achieved using these initiatives and help ensure that the appropriate decisions are made today. 
Building on the conclusions of each of the papers in this special issue, the main areas of interest that might be included in a future research programme examining public involvement in the deployment of (next generation) telecommunication networks are as follows (of course, this list is not intended to be either comprehensive or closed):

(1) What is the status of the "new" public or "semi-public" deployments? What are their main characteristics and under which conditions they are being deployed? What lessons can be learned from local networks that have been built in the past?

(2) How are the management and operation of these networks organised? What are the formulas being used to defray their cost?

(3) What advantages/disadvantages does public management entail as opposed to private management? What particularities can result from the involvement of local authorities in promoting or overseeing these projects?

(4) To what regulations, if any, should public or "mixed" networks be subject? What are the future role and scope of universal service?

(5) What is to be expected of the future results of publicly supported NGN in terms of efficiency? What strategies can guarantee their survival or even their economic success?

(6) Are there any alternatives to direct public investment that might allow us to reach objectives similar to those stated?

(7) What are the relationships among new policy agendas and next-generation developments in communications, particularly with regard to elnclusion, eHealth, eGovernment, eParticipation and Green-lCT agendas?

(8) What is the role of sustainability within the public-private interplay in next-generation communications?

\section{Acknowledgments}

The guest editors would like to highlight that the foundation for this special issue was the "Public/Private Interplay in Next-Generation Communications" conference, held in Seville, Spain from 10 to 12 December 2008. Thus, the editors would like to thank the event organiser, Universidad Nacional de Educación a Distancia (UNED), supported by Junta de Andalucía (Regional Government of Andalusia) and with the collaboration of Columbia Institute for Tele-[nformation (CIT]-Columbia University, New York).

\section{References}

Calzada, J., \& Dávalos, A. (2005). Cooperatives in Bolivia: Customer ownership of the local loop. Telecommunicatians Policy, 29(5-6), 387-407.

Gauld, R., Goldfinch, S., \& Horsbuigh, 5. (2010). Do they want it? Do they use it? The 'demand-side' of e-Government in Austialia and New Zealand. Government Information Quarterly, 27(2), 177-186.

Gibbons, J., \& Ruth, S. (2006). Municipal Wi-Fi: Big wave or wipeout? IEEE Internet Computing, 10(3), 66-71.

Gomez-Barroso. J. L., \& Fejjó, C. (2010). Volition versus feasibility: State aid when aid is looked upon favourably: The broadband example. European joumal of Low and Econamics, Advance online publication. 10.1007/s10657-010-9159-x.

Goth, G. (2009). Municipal wireless gets new emphasis-Rethinking the infrastructure cloud. IEEE Internet Computing. 13(6), 6-8.

Mandviwalla, M., Jain. A., Fesenmaier. J., Smith. J., Weinberg. P., \& Meyers, G. (2008). Municipal broadband wireless networks. Communications of the ACM. $51(2), 72-80$.

Nattermann, P. M., \& Murphy. D. D. (1998). The Finish telecommunications market-Advantage of local access incumbency. Telecommunications Policy. $22(9), 757-773$.

Strover, S., \& Mun, S. H. (2006). Wireless broadband, communities, and the shape of things to come. Government Injoimation Quarterly, 23(3-4), 348-358.

José Luis Gómez-Barroso*, Claudio Feijóo

UNED-Universidad Nacional de Educación a Distancia.

Economia Aplicada e Historia Económica.

$P^{c}$ Senda del Rey, 11, 28040 Madrid, Spain

E-mail address: jlgomez@cee.uned.es (].L. Gómez-Barroso) 